\title{
Study on the Hippocampal Neuron's Minimal Models' Discharge Patterns
}

\author{
Yueping Peng \\ Engineering College of Armed Police Force, 710086, Xi'an, China \\ Email: percy001@163.com \\ Haiying $\mathrm{Wu}$ \\ Engineering College of Armed Police Force, 710086, Xi'an, China \\ Email: percy7402@sohu.com \\ Nan Zou \\ Engineering College of Armed Police Force, 710086, Xi'an, China \\ Email: percy001@sina.com
}

\begin{abstract}
The hippocampal CA1 pyramid neuron has plenty of discharge actions. The one-compartment model of CA1 pyramid neuron developed by David is a ninedimension complex dynamic model. In the thesis, the currents related to the nine-dimension complex model are analyzed and classified by the model's reduction theory and methods based on neurodynamics, and four minimal models are gotten: $I_{N a}+I_{K d r}$-minimal model, $I_{N a}+I_{M}$-minimal model, $I_{N a}+I_{C a}+I_{y}$-minimal model, and $I_{N a}+I_{C a}+I_{S A H P}$-minimal model. These minimal models have plenty of dynamic actions, and under the current's stimulation, they can all generate regular discharge and have period discharge pattern, bursting pattern, the chaos discharge pattern, and so on. Compared with the initial nine-dimension complex model, these minimal models' dimension are much reduced, and are more convenient to numerical simulation, calculating, and analyzing. In addition, these minimal models provide a simpler and flexible method to discuss the specific currents' dynamic characteristics and functions of the initial nine-dimension complex model by the theory of neurodynamics.
\end{abstract}

Index Terms—neuron, the minimal model, discharge pattern

\section{INTRODUCTION}

In the 1990s, neuron modeling in hippocampal region has been becoming the research hotspot in the field of neural science. Depended on electrophysiological experiments and new technologies such as optics imaging, some models of hippocampal pyramidal Neuron based on ionic conductance have been successfully constructed; The work of R.D.Traub's research team is the most excellent[1-20]. In 1991, based on the electrophysiological experiment data of Guinea pig

The corresponding author is Yueping Peng. hippocampal neurons, R.D.Traub had developed a 19compartment cable model of CA3 pyramidal neuron; Based on the model, R.D.Traub's research team had deeply studied these issues such as hippocampal neuronal network, EEG rhythm, plasticity of hippocampal neuron Synapse, electrical coupling influence on hippocampal neuron's high frequency oscillation, and cortical neuron's rapid oscillation[8-10]. Based on R.D.Traub research team's achievements and the electrophysiological experiment data, Warman had developed a 16compartment cable model of CA1 pyramidal neuron based on ionic conductance by computer simulation, and had successfully simulated electrophysiological features and experimental results of CA1 pyramid neuron[11].

The hippocampal CA1 pyramid neuron has plenty of discharge actions. Yue found that bursting behavior persists in adult CA1 pyramidal cells after almost complete truncation of the apical dendrites. The mechanism of bursting is different from the "ping-pong" mechanism, which depends on the integrity of apical dendrites[12-14]. Based on the CA1 pyramidal neuron's membrane ionic channel theory and its electrophysiological experimental data, according to the basic frame of $\mathrm{H}-\mathrm{H}$ class model, David had developed one-compartment model of CA1 Pyramidal Neuron by neurodynamic theory[15]. The model is different from former multi-compartment cable models of the hippocampal pyramid neuron. This model omits the effects of the apical dendrites and the complexity is reduced, which not only can simulate many electrophysiological features and experimental results of the hippocampal CA1 pyramid neuron, but also can spontaneously generate regular firing, tonic firing, rhythmic bursting, and so on.

In this study, we take the nine-dimension onecompartment complex model of CA1 pyramid neuron developed by David as the object, and classify the 
currents related to the model, and simplify the model by the minimal model's reduction theory and method, and get the minimal models, and discuss these minimal models' dynamic characteristics by neurodynamic theory and methods.

\section{The Nine-Dimension Model OF CA1 PyrAmid NEURON AND ITS DISCHARGE PATTERNS}

The nine-dimension one-compartment model of CA1 pyramid neuron developed by David has multiple time scale dynamic action. The current balance equation of the model is as follows:

$C \frac{d V}{d t}=-I_{L}-I_{N a}-I_{N a P}-I_{K d r}-I_{A}-I_{M}-I_{C a}-I_{Y}-I_{\text {sAHP }}+I_{A p p}$

Where $\mathrm{C}$ is the membrane capacitance; $\mathrm{V}$ is the membrane potential; $I_{L}$ is the leakage current; $I_{N a}$ is the transient $\mathrm{Na}^{+}$current; $\mathrm{I}_{\mathrm{NaP}}$ is the persistent $\mathrm{Na}^{+}$current; $\mathrm{I}_{\mathrm{Kdr}}$ is the delay rectification $\mathrm{K}^{+}$current; $\mathrm{I}_{\mathrm{A}}$ is the A-type instantaneous $\mathrm{K}^{+}$current; $\mathrm{I}_{\mathrm{M}}$ is the muscarine-sensitive $\mathrm{K}^{+}$ current; $\mathrm{I}_{\mathrm{Ca}}$ is the high-threshold $\mathrm{Ca}^{2+}$ current; $\mathrm{I}_{\mathrm{y}}$ is the fast $\mathrm{Ca}^{2+}$-activated $\mathrm{K}^{+}$current; $\mathrm{I}_{\mathrm{S}}{ }_{\mathrm{AHP}}$ is the slow $\mathrm{Ca}^{2+}$ activated $\mathrm{K}^{+}$current; $\mathrm{I}_{\mathrm{APP}}$ is the stimulation current.

Currents of above balance equation are changed into their corresponding ionic conductance forms, and the eight corresponding time variables are also added. Therefore, the models are changed into set of ninedimension ordinary differential equations,

$$
\begin{aligned}
& C \frac{d V}{d t}=-g_{L}\left(V-V_{L}\right)-g_{N a} m_{\infty}^{3}(V) h\left(V-V_{N a}\right) \\
&-g_{N a P} p_{\infty}(V)\left(V-V_{N a}\right)-g_{K d r} n^{4}\left(V-V_{K}\right) \\
&-g_{A} a_{\infty}^{3}(V) b\left(V-V_{K}\right)-g_{M} z\left(V-V_{K}\right) \\
&-g_{C a} r^{2}\left(V-V_{C a}\right)-g_{y} d_{\infty}\left(\left[C a^{2+}\right]_{i}\right) y\left(V-V_{K}\right) \\
&-g_{\text {sAHP }} q\left(V-V_{K}\right)+I_{A p p} ; \\
& \frac{d h}{d t}= \frac{h_{\infty}(V)-h}{\tau_{h}(V)} ; \\
& \frac{d n}{d t}=\frac{n_{\infty}(V)-n}{\tau_{n}(V)} ; \\
& \frac{d b}{d t}=\frac{b_{\infty}(V)-b}{\tau_{b}} ; \\
& \frac{d z}{d t}=\frac{z_{\infty}(V)-z}{\tau_{z}} ; \\
& \frac{d q}{d t}=\frac{q_{\infty}\left(\left[C a^{2+}\right]_{i}\right)-q}{\tau_{q}} ; \\
& \frac{d y}{d t}=\frac{r_{\infty}(V)-y}{\tau_{y}} ; \\
& y_{i}
\end{aligned}
$$

The equation model has nine time variables: the membrane potential variable $\mathrm{V}$, transient $\mathrm{Na}^{+}$current inactivation variable $h$, delayed rectified $\mathrm{K}^{+}$current activation variables $\mathrm{n}$, A-type instantaneous $\mathrm{K}^{+}$current inactivation variables $\mathrm{b}$, muscarine-Sensitive $\mathrm{K}^{+}$currentactivated variables $\mathrm{Z}$, high-threshold $\mathrm{Ca}^{2+}$ currentactivated variable $\mathrm{r}$, fast $\mathrm{Ca}^{2+}$-activated $\mathrm{K}^{+}$currentactivated variable $\mathrm{y}$, slow $\mathrm{Ca}^{2+}$-activated $\mathrm{K}^{+}$currentactivated variable $\mathrm{q}$, and intramembrane calcium ion concentration variable $\left[\mathrm{Ca}^{2+}\right]$ i. At numerical calculation, the values of model parameters refer to appendix A. In addition, the state variable of the model is $(\mathrm{V}, \mathrm{h}, \mathrm{n}, \mathrm{b}, \mathrm{z}, \mathrm{r}$, $\left.\mathrm{y}, \mathrm{q},\left[\mathrm{Ca}^{2+}\right] \mathrm{i}\right)$, and the initial state of the model is $(-65,0.1$, $0.1,0.1,0.1,0.1,0.1,0.1,0.05)$.

The nine-dimension model of CA1 pyramid neuron showed by formula (1) can spontaneously generate regular firing, tonic firing, rhythmic bursting, and so on[15]. Based on MATLAB simulation methods, several common discharge patterns of the nine-dimension model of CA1 pyramid neuron under different currents' stimulation are showed in Figure 1.
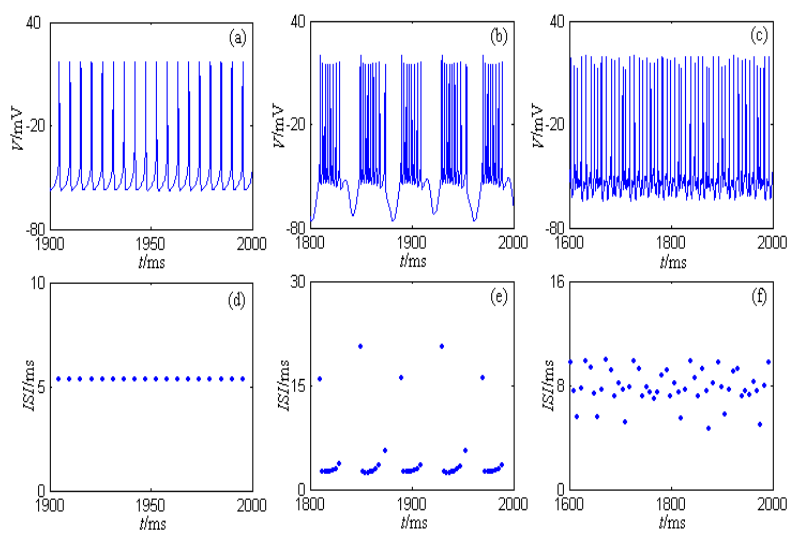

Figure 1. Discharge patterns of the nine-dimension model of CA1 pyramid neuron. (a) and (d) are the period 1 discharge pattern. (b) and (e) are the bursting discharge pattern. (c) and (f) are the chaos discharge pattern.

\section{The HipPocAmpal CA1 PyRAMID NEURON'S Minimal Models AND ITS DischaRge PATTERNS}

According to the theory of neurodynamics, the high dimension neuron model based on ionic conductance can be reduced to the low dimension models such as the minimal model[23]. The minimal model usually includes one amplifying and one resonant (recovery) gating variable (plus an Ohmic leak current)[23], and it has following characters: It has a limit cycle attractor, at least for some values of parameters, and can generate tonic firing; If one removes any current or gating variable, the minimal model has only equilibrium attractors for any values of parameters, and can't generate firing[21-26]. It must be noted that the dynamic characteristics of the reduced models(including the minimal model) can't globally express the characteristics of the primary model, 
but it is very convenient to analyze the specific dynamic characteristics of the neuron model.

The one-compartment model of CA1 pyramid neuron developed by David is a nine-dimension complex dynamic model. According to the model's reduction methods based on neurodynamics, the nine-dimension complex model can be reduced to the low dimension model by the dimension reduction, and several following minimal models which can generate regular firing are gotten.

\section{A. $I_{N a}+I_{K d r}$-Minimal Model}

The minimal model consists of the transient $\mathrm{Na}^{+}$ current $\left(I_{N a}\right)$, the delay rectification $\mathrm{K}^{+} \operatorname{current}\left(I_{K d r}\right)$, and the leakage current $\left(I_{L}\right)$. The descriptive differential equation is as follows,

$$
\begin{aligned}
C \frac{d V}{d t}= & -g_{L}\left(V-V_{L}\right)-g_{N a} m_{\infty}^{3}(V) h\left(V-V_{N a}\right) \\
& -g_{K d r} n^{4}\left(V-V_{K}\right)+I_{A P P} \\
\frac{d h}{d t}= & \frac{h_{\infty}(V)-h}{\tau_{h}(V)} \\
\frac{d n}{d t}= & \frac{n_{\infty}(V)-n}{\tau_{n}(V)}
\end{aligned}
$$

Where the values of parameters related to the model equation are showed in appendix A.

Under the current's stimulation, the minimal model described by formula (2) can generate period discharge pattern, bursting pattern, the chaos discharge pattern, and so on. The minimal model's discharge patterns and the phase plane portraits are showed in Figure 2, where the stimulation currernt is the direct current (the amplitude is $5 n A)$ and the half wave sine current (the amplitude is $10 \mathrm{nA}$ and the period is $5 \mathrm{~ms}$ ). The model's simulation time is $0 \sim 2000 \mathrm{~ms}$, and the graphing time interval is 1000 2000ms.

From Figure 2, the neuron generates period 1 discharge pattern under the direct current (the amplitude is $5 \mathrm{nA}$ ); and the neuron generates period 2 discharge pattern under the half wave sine current (the amplitude is 10nA and the period is $5 \mathrm{~ms}$ ).
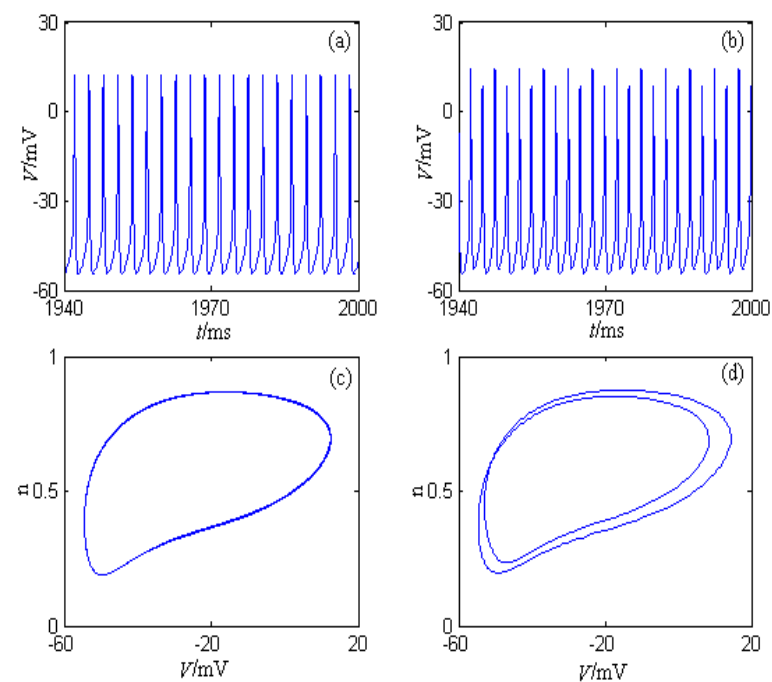

Figure 2. $I_{N a}+I_{K d r}$-Minimal model's discharge patterns and the phase plane portraits. (a) The changing chart of the membrane potential with time under stimulation of the direct current (the amplitude is $5 \mathrm{nA}$ ). (b) The changing chart of the membrane potential with time under stimulation of the half wave sine current (the amplitude is $10 \mathrm{nA}$ and the period is $5 \mathrm{~ms}$ ). (c) The phase plane portrait under stimulation of the direct current (the amplitude is $5 \mathrm{nA}$ ). (d) The phase plane portrait under stimulation of the half wave sine current (the amplitude is $10 \mathrm{nA}$ and the period is $5 \mathrm{~ms}$ ).

\section{B. $I_{N a}+I_{M}$-Minimal Model}

The minimal model consists of the transient $\mathrm{Na}^{+}$ current $\left(I_{N a}\right)$, the muscarine-sensitive $\mathrm{K}^{+}$current $\left(I_{M}\right)$, and the leakage current $\left(I_{L}\right)$. The descriptive differential equation is as follows,

$$
\begin{aligned}
C \frac{d V}{d t} & =-g_{L}\left(V-V_{L}\right)-g_{N a} m_{\infty}^{3}(V) h\left(V-V_{N a}\right)-g_{M} z\left(V-V_{K}\right)+I_{A p p} \\
\frac{d h}{d t} & =\frac{h_{\infty}(V)-h}{\tau_{h}(V)} \\
\frac{d z}{d t} & =\frac{z_{\infty}(V)-z}{\tau_{z}}
\end{aligned}
$$

Where the values of parameters related to the model equation are showed in appendix A.

Under the current's stimulation, the minimal model described by formula (3) can generate slow period discharge pattern, and so on. The minimal model's discharge patterns and the phase plane portraits are showed in Figure 3, where the stimulation currernt is the direct current (the amplitude is $5 \mathrm{nA}$ ) and the half wave sine current (the amplitude is 10nA and the period is $10 \mathrm{~ms}$ ). The model's simulation time is $0 \sim 2000 \mathrm{~ms}$, and the graphing time interval is $1000 \sim 2000 \mathrm{~ms}$. 

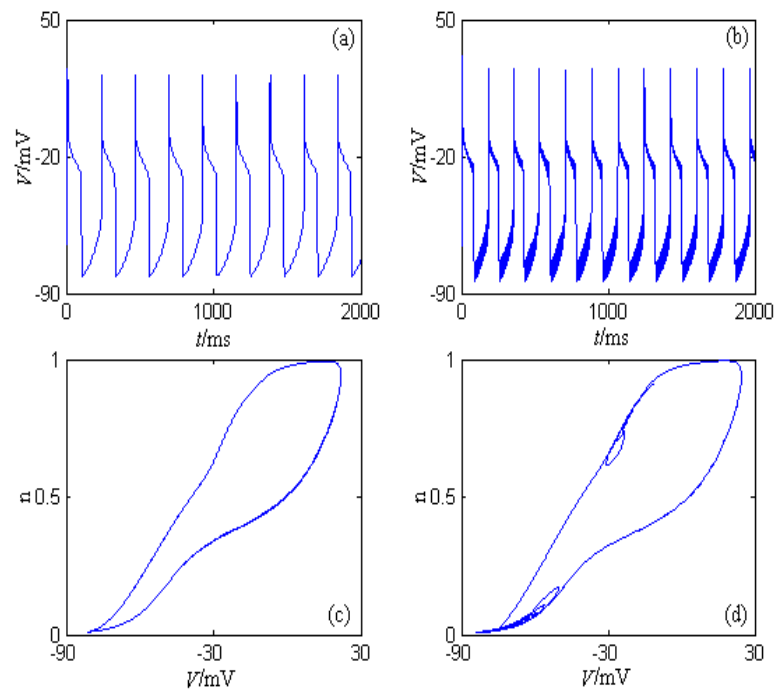

Figure 3. $I_{N a}+I_{M}$-Minimal model's discharge patterns and the phase plane portraits. (a) The changing chart of the membrane potential with time under stimulation of the direct current (the amplitude is $5 n A$ ). (b) The changing chart of the membrane potential with time under stimulation of the half wave sine current (the amplitude is $10 \mathrm{nA}$ and the period is $10 \mathrm{~ms}$ ). (c) The phase plane portrait under stimulation of the direct current (the amplitude is $5 n A$ ). (d) The phase plane portrait under stimulation of the half wave sine current (the amplitude is $10 \mathrm{nA}$ and the period is $10 \mathrm{~ms}$ ).

From Figure 2, the neuron generates period 1 discharge pattern under the direct current (the amplitude is $5 \mathrm{nA}$ ). The neuron also generates period 1 discharge pattern under the half wave sine current (the amplitude is $10 \mathrm{nA}$ and the period is $10 \mathrm{~ms}$ ); However, because frequency of the stimulation current is much higher than the intrinsic discharge frequency of the neuron model, the "spike" phenomenon(Figure 3 (b)) comes into being when the stimulation current is added to the intrinsic discharge pattern of the neuron model. In addition, $I_{N a}+I_{M}-$ Minimal Model's discharge frequency is much lower than $I_{N a}+I_{M}$-Minimal Model's discharge frequency, which is mainly caused by the intrinsic characteristics of the muscarine-sensitive $\mathrm{K}+$ current $\left(I_{M}\right)$.

\section{C. $I_{\mathrm{Na}}+I_{\mathrm{Ca}}+I_{y}$-Minimal Model}

The minimal model consists of the transient $\mathrm{Na}^{+}$ current $\left(I_{N a}\right)$, the high-threshold $\mathrm{Ca}^{2+}$ current $\left(I_{\mathrm{Ca}}\right)$, the fast $\mathrm{Ca}^{2+}$-activated $\mathrm{K}^{+} \operatorname{current}\left(I_{Y}\right)$, and the leakage current $\left(I_{L}\right)$. The descriptive differential equation is as follows,

$$
\begin{aligned}
C \frac{d V}{d t}= & -g_{L}\left(V-V_{L}\right)-g_{N a} m_{\infty}^{3}(V) h\left(V-V_{N a}\right)-g_{C a} r^{2}\left(V-V_{C a}\right) \\
& -g_{y} d_{\infty}\left(\left[C a^{2+}\right]_{i}\right) y\left(V-V_{K}\right)+I_{A p p} \\
\frac{d h}{d t}= & \frac{h_{\infty}(V)-h}{\tau_{h}(V)} \\
\frac{d r}{d t}= & \frac{r_{\infty}(V)-r}{\tau_{r}} \\
\frac{d q}{d t}= & \frac{q_{\infty}\left(\left[C a^{2+}\right]_{i}\right)-q}{\tau_{q}}
\end{aligned}
$$

$$
\frac{d\left[C a^{2+}\right]_{i}}{d t}=-v g_{C a} r^{2}\left(V-V_{C a}\right)-\frac{\left[C a^{2+}\right]_{i}}{\tau_{C a}}
$$

Where the values of parameters related to the model equation are showed in appendix A.
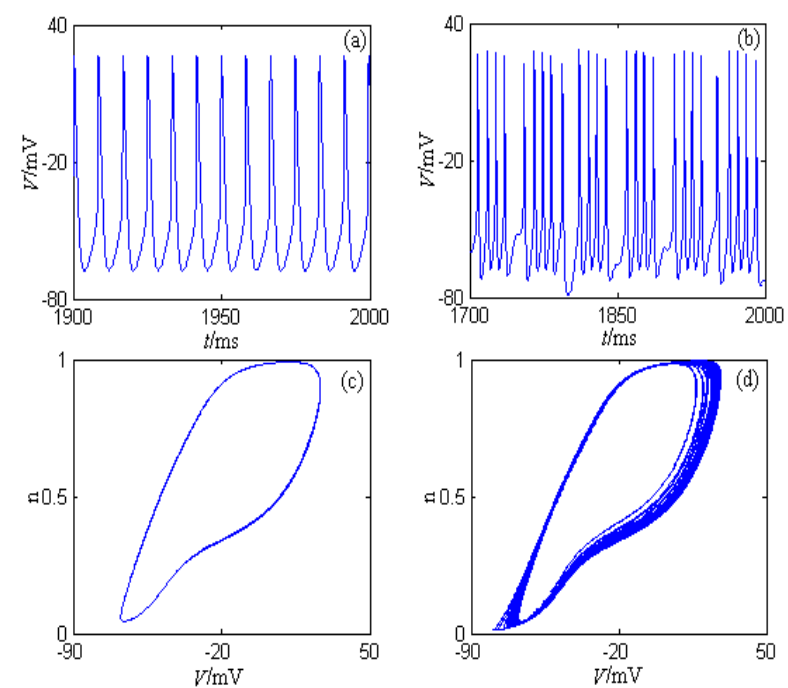

Figure 4. $I_{N a}+I_{C a}+I_{y}$-Minimal model's discharge patterns and the phase plane portraits. (a) The changing chart of the membrane potential with time under stimulation of the direct current (the amplitude is $5 n A)$. (b) The changing chart of the membrane potential with time under stimulation of the half wave sine current (the amplitude is $10 \mathrm{nA}$ and the period is $50 \mathrm{~ms}$ ). (c) The phase plane portrait under stimulation of the direct current (the amplitude is $5 \mathrm{nA}$ ). (d) The phase plane portrait under stimulation of the half wave sine current (the amplitude is $10 \mathrm{nA}$ and the period is $50 \mathrm{~ms}$ ).

Under the current's stimulation, the minimal model described by formula (4) can generate period discharge pattern, bursting pattern, the chaos discharge pattern, and so on. The minimal model's discharge patterns and the phase plane portraits are showed in Fig. 4, where the stimulation currernt is the direct current (the amplitude is $5 n A$ ) and the half wave sine current (the amplitude is $10 \mathrm{nA}$ and the period is $50 \mathrm{~ms}$ ). The model's simulation time is $0 \sim 2000 \mathrm{~ms}$, and the graphing time interval is 1000 2000ms.

From Fig.4, the neuron generates period 1 discharge pattern under the direct current (the amplitude is $5 \mathrm{nA}$ ); The neuron generates bursting discharge pattern under the half wave sine current (the amplitude is $10 \mathrm{nA}$ and the period is $50 \mathrm{~ms}$ ), and the firing number of each bursting is different.

\section{D. $I_{N a}+I_{C a}+I_{s A H P}$-Minimal Model}

The minimal model consists of the transient $\mathrm{Na}^{+}$ current $\left(I_{N a}\right)$, the high-threshold $\mathrm{Ca}^{2+}$ current $\left(I_{\mathrm{Ca}}\right)$, the slow $\mathrm{Ca}^{2+}$-activated $\mathrm{K}^{+}$current $\left(I_{\text {sAHP }}\right)$, and the leakage current $\left(I_{L}\right)$. The descriptive differential equation is as follows,

$$
C \frac{d V}{d t}=-g_{L}\left(V-V_{L}\right)-g_{N a} m_{\infty}^{3}(V) h\left(V-V_{N a}\right)-g_{C a} r^{2}\left(V-V_{C a}\right)
$$




$$
\begin{aligned}
&-g_{\text {SAHP }} q\left(V-V_{K}\right)+I_{A p p} \\
& \frac{d h}{d t}= \frac{h_{\infty}(V)-h}{\tau_{h}(V)} \\
& \frac{d r}{d t}= \frac{r_{\infty}(V)-r}{\tau_{r}} \\
& \frac{d q}{d t}= \frac{q_{\infty}\left(\left[C a^{2+}\right]_{i}\right)-q}{\tau_{q}} \\
& \frac{d\left[C a^{2+}\right]_{i}}{d t}=-v g_{C a} r^{2}\left(V-V_{C a}\right)-\frac{\left[C a^{2+}\right]_{i}}{\tau_{C a}}
\end{aligned}
$$

Where the values of parameters related to the model equation are showed in appendix A.

Under the current's stimulation, the minimal model described by formula (5) can generate slow period discharge pattern, and so on. The minimal model's discharge patterns and the phase plane portraits are showed in Fig. 5, where the stimulation currernt is the direct current (the amplitude is $5 n \mathrm{~A}$ ) and the half wave sine current (the amplitude is 20nA and the period is $5 \mathrm{~ms}$ ). The model's simulation time is $0 \sim 2000 \mathrm{~ms}$, and the graphing time interval is $1000 \sim 2000 \mathrm{~ms}$.

From Fig.5, the neuron generates period 1 discharge pattern under the direct current (the amplitude is $5 \mathrm{nA}$ ). The neuron also generates period 1 discharge pattern under the half wave sine current (the amplitude is 20nA and the period is 5ms); However, because frequency of the stimulation current is much higher than the intrinsic discharge frequency of the neuron model, the "spike" phenomenon (Fig.5 (b)) comes into being when the stimulation current is added to the intrinsic discharge pattern of the neuron model. In addition, $I_{N a}+I_{M}-$ Minimal Model's discharge frequency is much lower than discharge frequency of Minimal Models (described by formula (2) and (4)), which is mainly caused by the intrinsic characteristics of the slow Ca2+-activated $\mathrm{K}^{+}$ current $\left(I_{\text {SAHP }}\right)$.
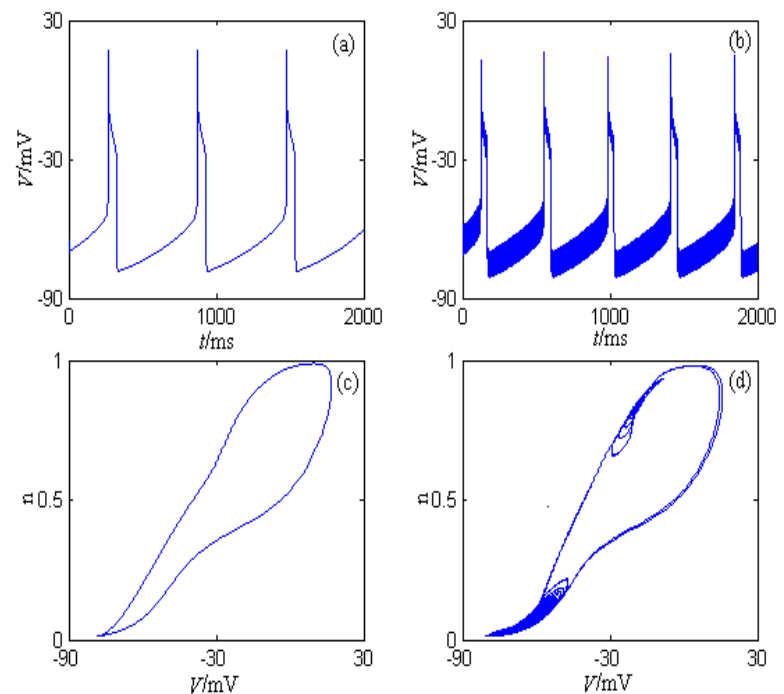

Figure 5. $I_{\mathrm{Na}}+I_{\mathrm{Ca}}+I_{\mathrm{SAHP}}$-Minimal model's discharge patterns and the phase plane portraits. (a) The changing chart of the membrane potential with time under stimulation of the direct current (the amplitude is $5 \mathrm{nA}$ ). (b) The changing chart of the membrane potential with time under stimulation of the half wave sine current (the amplitude is 20nA and the period is $5 \mathrm{~ms}$ ). (c) The phase plane portrait under stimulation of the direct current (the amplitude is $5 \mathrm{nA}$ ). (d) The phase plane portrait under stimulation of the half wave sine current (the amplitude is $20 \mathrm{nA}$ and the period is $5 \mathrm{~ms}$ ).

\section{CONCLUSION}

In the thesis, the currents related to the nine-dimension one-compartment complex model of CA1 pyramid neuron developed by David are analyzed and classified by the model's reduction theory and methods based on neurodynamics, and four minimal models are gotten: $I_{N a}+I_{K d r}$-minimal model, $I_{N a}+I_{M}$-minimal model, $I_{N a}+I_{C a}+I_{y}$-minimal model, and $I_{N a}+I_{C a}+I_{S A H P}-$ minimal model. These minimal models have plenty of dynamic actions, and under the current's stimulation, they can all generate regular discharge and have period discharge pattern, bursting pattern, the chaos discharge pattern, and so on.

Compared with the initial nine-dimension complex model, these minimal models' dimension are much reduced, and are more convenient to numerical simulation, calculating, and analyzing. In addition, though these minimal models can't globally express characteristics and functions of the primary ninedimension complex model, they provide a simpler and flexible method to discuss the specific currents' dynamic characteristics and functions of the initial nine-dimension complex model by the theory of neurodynamics.

\section{APPENDIX A}

Parameters' values of the nine-dimension onecompartment complex model of CA1 pyramid neuron developed by David are as follow:

$C=1 u F / \mathrm{cm}^{2}$;

$g_{L}=0.05 \mathrm{mS} / \mathrm{cm}^{2}$;

$V_{L}=-70 m V$;

$g_{\mathrm{Na}}=35 \mathrm{mS} / \mathrm{cm}^{2}$;

$g_{N a P}$ is about $0 \sim 0.41 \mathrm{mS} / \mathrm{cm}^{2}$;

$g_{K d r}=6 \mathrm{mS} / \mathrm{cm}^{2}$;

$g_{A}=1.4 \mathrm{mS} / \mathrm{cm}^{2}$;

$g_{M}=1 \mathrm{mS} / \mathrm{cm}^{2}$;

$V_{\mathrm{Na}}=55 \mathrm{mV}$;

$V_{K}=-90 m V$;

$g_{C a}$ is about $0 \sim 0.2 \mathrm{mS} / \mathrm{cm}^{2}$;

$g_{y}=10 \mathrm{mS} / \mathrm{cm}^{2}$;

$g_{\text {SAHP }}=5 \mathrm{mS} / \mathrm{cm}^{2}$;

$V_{C a}=120 m V$;

$$
m_{\infty}(V)=\frac{1}{1+\exp \left(\frac{-30-V}{9.5}\right)} ;
$$




$$
\begin{aligned}
& p_{\infty}(V)=\frac{1}{1+\exp \left(\frac{\theta_{p}-V}{3}\right)} \\
& -47 m V \leq \theta_{p} \leq-41 m V ; \\
& a_{\infty}(V)=\frac{1}{1+\exp \left(\frac{-50-V}{20}\right)} ; \\
& d_{\infty}\left(\left[\mathrm{Ca}^{2+}\right]_{i}\right)=\frac{1}{1+\frac{6}{\left[C a^{2+}\right]_{i}}} ; \\
& h_{\infty}(V)=\frac{1}{1+\exp \left(\frac{-45-V}{-7}\right)} \text {; } \\
& \tau_{h}(V)=0.1+0.75 \times \frac{1}{1+\exp \left(\frac{-40.5-V}{-6}\right)} ; \\
& n_{\infty}(V)=\frac{1}{1+\exp \left(\frac{-35-V}{10}\right)} \text {; } \\
& \tau_{n}(V)=0.1+0.5 \times \frac{1}{1+\exp \left(\frac{-27-V}{-15}\right)} ; \\
& b_{\infty}(V)=\frac{1}{1+\exp \left(\frac{-80-V}{-6}\right)} ; \\
& \tau_{b}=15 \mathrm{~ms} \text {; } \\
& z_{\infty}(V)=\frac{1}{1+\exp \left(\frac{-39-V}{5}\right)} ; \\
& \tau_{z}=75 m s ; \\
& r_{\infty}(V)=\frac{1}{1+\exp \left(\frac{-20-V}{10}\right)} ; \\
& \tau_{r}=1 m s ; \\
& y_{\infty}(V)=\frac{1}{1+\exp \left(\frac{-30-V}{7}\right)} ; \\
& \tau_{y}=2 m s ; \\
& \tau_{q}=450 \mathrm{~ms} \text {; } \\
& v=0.13 \mathrm{~cm}^{2} /(m s \times \mu A) \text {; } \\
& q_{\infty}\left(\left[\mathrm{Ca}^{2+}\right]_{i}\right)=\frac{1}{1+\frac{16}{\left[\mathrm{Ca}^{2+}\right]_{i}^{4}}} ; \\
& \tau_{C a}=13 m s ;
\end{aligned}
$$

ACKNOWLEDGMENT
This work is supported by the basic research project of Engineering College of Armed Police Force. The project name is "Study on the Synchronization Mechanism of Uncoupled Neurons (No. WJY201015).

In addition, the authors would like to thank "The 2nd International Conference on Biomedical Engineering and Computer Science (ICBECS 2011)" for providing the chance and really appreciate the anonymous reviewers for the valuable comments on the paper.

\section{REFERENCES}

[1] Urbani A and Belluzzi O, "Riluzole inhibits the persistent sodium current in mammalian CNS neurons," Eur $J$ Neurosci, vol. 12, pp. 3567-3574, January 2000.

[2] Vasilyev DV and Barish ME, "Postnatal development of the hyperpolarization-activated excitatory current Ih in mouse hippocampal pyramidal neurons,” J Neurosci, vol. 22, pp. 8992-9004, April 2002.

[3] Vervaeke $\mathrm{K}, \mathrm{Hu} \mathrm{H}$, Graham LJ, and Storm JF, "Contrasting effects of the persistent Na_current on neuronal excitability and spike timing," Neuron, vol. 49, pp. 257-270, May 2006.

[4] Shuai J, Bikson M, Hahn PJ, Lian J, and Durand DM, "Ionic mechanisms underlying spontaneous CA1 neuronal firing in Ca2+-free solution,” Biophys $J$, vol. 84, pp. 20092011, April 2003.

[5] Gu N, Vervaeke K, Hu H, and Storm JF, "Kv7/KCNQ/M and $\mathrm{HCN} / \mathrm{h}$, but not KCa2/SK channels, contribute to the somatic medium after-hyperpolarization and excitability control in CA1 hippocampal pyramidal cells,” J Physiol, vol. 566, pp. 689-715, June 2005.

[6] Chen S, Yue C, and Yaari Y, "A transitional period of calcium-dependent bursting triggered by spike backpropagation into apical dendrites in developing hippocampal neurons,” J Physiol, vol. 567, pp. 79-93, March 2005.

[7] Metz AE, Jarsky T, Martina M, and Spruston N, "R-type calcium channels contribute to afterdepolarization and bursting in hippocampal CA1 pyramidal neurons," $J$ Neurosci, vol. 25, pp. 5763-5773, April 2005.

[8] Traub RD, Wong RK, Miles R, and Michelson H, “A model of a CA3 hippocampal pyramidal neuron incorporating voltage-clamp data on intrinsic conductances," J Neurophysiol, vol. 66, pp. 635-649, 1991.

[9] Traub RD and Miles R, "Neuronal networks of the hippocampus,” New York: Cambridge, 1991.

[10] Traub RD, Jefferys JGR, Miles R, Whittington MA, and To'th $\mathrm{K}$, "A branching dendritic model of a rodent CA3 pyramidal neurone,” J Physiol, vol. 481, pp. 79-95, February 1994.

[11] Warman EN, Durand DM, and Yuen GL, "Reconstruction of hippocampal CA1 pyramidal cell electrophysiology by computer simulations,” J Neurophysiol, vol. 71, pp. 20332045, April 1994.

[12] Yue C, Remy S, Su H, Beck H, and Yaari Y, "Proximal persistent $\mathrm{Na}+$ channels drive spike afterdepolarizations and associated bursting in adult CA1 pyramidal cells," $J$ Neurosci, vol. 25, pp. 9704-9720, 2005.

[13] Yue C and Yaari Y, "KCNQ/M channels control spike afterdepolarization and burst generation in hippocampal neurons,” J Neurosci, vol. 24, pp. 4614-4624, 2004.

[14] Yue C and Yaari Y, "Axo-somatic and apical dendritic Kv7/M channels differentially regulate the intrinsic 
[15] excitability of adult rat CA1 pyramidal cells,” $J$ Neurophysiol, vol. 95, pp. 3480-3495, April 2006.

[16] David Golomb, Cuiyong Yue, and Yoel Yaari, "Contribution of Persistent $\mathrm{Na}+$ Current and M-Type $\mathrm{K}+$ Current to Somatic Bursting in CA1 Pyramidal Cells: Combined Experimental and Modeling Study,” $J$ Neurophysiol, vol. 96, pp. 1912-1926, 2006.

[17] Berger TW, "Long-term potentiation of hippocampal synaptic transmission affects rate of behavioral learning," Science, vol. 224, pp. 627-630, 1984.

[18] Xiao MY, Zhuo Q and Nicoll RA, "Metabotropic glutamate receptor activation causes a rapid redistribution of AMPA receptors,” Neuropharmacology, vol.41, pp. 664-671, June 2001.

[19] Mellentin C and Abraham WC, "Priming stimulation of group II metabotropic glutamate receptors inhibits the subsequeng induction of rat hippocampal long-term depression in vitro," Neurosci Lett, vol.307, pp.13-16, January 2001.

[20] Hammarstrom AK, Gage PW, "Hypoxia and persistent sodium current,” Eur Biophys J, Vol.31, pp. 323-330, 2002.

[21] Horn EM, waldrop TG, "Hypoxic augmentation of fast2inactivating and persistent sodium currents in rat caudalhypothalamic neurons," J Neurophysiol, vol. 84, pp. 2572-2581, 2000.

[22] R. M. Ghigliazza and P. Holmes, "Minimal models of bursting neurons: How multiple current, conductances and timescales affect bifurcation diagrams," SIAM Journal on Applied Dynamical Systems, 2004.

[23] Miaoxing Yao and Fangqi Chen, "Mathematical Foundation of Nonlinear Theory," Tianjin: Tianjin University Press, 2005.

[24] Eugene M.Izhikevich, "Dynamical Systems in Neuroscience: The Geometry of Excitability and Bursting," The MIT Press, 2005.

[25] Izhikevich E. M. and Hoppensteadt F.C., "Polychronous Wavefront Computations," International Journal of Bifurcation and Chaos, vol.19, pp. 1733-1739, 2009.

[26] Szatmary B. and Izhikevich E. M., "Spike-Timing Theory of Working Memory,” PLoS Computational Biology, vol.6, pp. e1000879, Auguest 2010.
[27] Wu Ying, Xu Jianxue, He Daihai, Jin Wuyin., "Study on nonlinear characteristic of two synchronizing uncoupled Hindmarsh-Rose neurons,” Acta Physica Sinica, vol.54, pp. 3457-3464, June 2005.

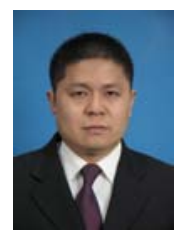

Yueping Peng was born in on 10 February, 1974. he got the Ph.D degree in Biomedical Engineering of Xi'an Jiaotong University in 2010. He received the B.S. degree in Communication Engineering and M.S. degree in Information Engineering, both from Engineering College of Armed Police Force, in 1997 and 2003, respectively. Now he is a member of China Association of Rehabilitation of Disabled Persons and of China Association of Biomedical Engineering. He is a professor, communication engineering department, Engineering College of Armed Police Force. He has pubilished over sixty papers in some science journals and joined thirteen research projects. His research interests are in the dynamic mechanism of neurons' injury and rehabilitation, the signal and information processing, and the neurodynamics and Its application.

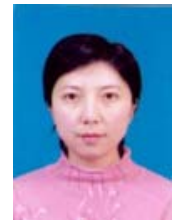

Haiying Wu was born in Shaanxi on 24 December, 1975. She obtained bachelor degree in July 1999 and graduated from Department of Computer Science in Northwestern University at Xi'an Shaanxi China. She obtained master degree in July 2006 and graduated from college of Computer Science in Shaanxi Normal University. Now she is a teacher in Engineering College of Armed Police Force. The main field of study is Access Control of information security and Artificial Intelligence.

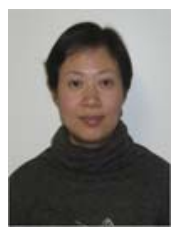

Nan Zou was born in Shaanxi on 23 September, 1975. She received the B.S. degree and the M.S. degree in Law, both from Northwest University, in 1998 and 2006, respectively. Now she is a teacher, the basic department, Engineering College of Armed Police Force. She has pubilished over twenty papers in some science journals and joined eight research projects. Her research interests are in the law application. 